\title{
Challenging Our Stories as Teacher Educators for Social Justice: Narrative as Professional Development
}

\author{
Michelle Page \\ University of Minnesota-Morris \\ Mary Curran \\ The State University of New Jersey
}

\section{Author Note}

Portions of this work were presented at the Annual Meeting of the American Educational Research Association in San Francisco, CA April 2006.

Correspondence concerning this article should be addressed to Michelle Page, Associate Professor \& Coordinator of Secondary Education, University of Minnesota-Morris, 108 Education Building, 600 E 4th St, Morris, MN 56267, (320) 589-6405 pagem@morris.umn.edu or Mary Curran, Associate Clinical Professor, Graduate School of Education, Rutgers, The State University of New Jersey , 10 Seminary Place, New Brunswick, NJ 08901, (732) 932-7496, 8101, mcurran@rci.rutgers.edu

\begin{abstract}
In this paper, we report on a collaborative self-study in which we reflect upon our practice as teacher educators through a critical multicultural and white studies framework. We developed a pedagogical tool for our own professional development as teacher educators, modeled on the type of narrative assignments we ask of our students. We wrote stories about difficult moments in our practice, shared these with colleagues and reflected upon their responses. In this activity, we aimed to practice what we preach, as we model our commitment to being life-long learners; our respect for the power of listening to others and considering multiple perspectives; and our constant desire to critique and transform our practice in ways that are more effective and contribute to the educational success of all students. Our analysis of our experience demands that we reconsider our assumptions about student learning, how we hold our students accountable, and how we are socialized as white women within the academy of higher education.
\end{abstract}

Keywords: narrative; teacher education; multicultural education 


\section{Challenging Our Stories as Teacher Educators for Social Justice: Narrative as Professional Development}

For many years, we have claimed identities as teacher educators for social justice because, in our lives and in our teaching, we work to raise awareness of and transform systems of inequity and oppression. While we value interpersonal, relationship-driven models of multicultural education, we believe that these fail to address institutional and systemic racism, privilege, and power. Through various projects in our communities and on our campuses we have aimed to dismantle systems of oppressions, and we want to empower our preservice teachers to do so as well. As teacher educators for social justice, we want our preservice teachers to critically examine the ideological and political complexity of difference and carry their critique into the world through advocacy and transformative practice (McLaren, 1994).

However, as we teach about difference, privilege, and power, we discover a tension between our desire to create safe environments in which we can tackle sensitive topics and the need to stir up the waters and awaken our students to the devastating ways that inequities occur right under our noses. We find ourselves in situations in which we want to draw our students' attention to their own discriminatory behaviors, as well. At times, we feel like we walk a fine line as we work to keep our students comfortable and open to dialogues about difference and equity, while wanting to make them uncomfortable so that they will notice, question, and work to transform the status quo in their future teaching practice. In this paper, we examine difficult moments in our teaching in order to analyze our pedagogical choices and locations as white teacher educators. We have often wondered if we are making our students uncomfortable enough. Perhaps we are not pushing hard enough to make our students listen, consider alternatives, and change.

Because of our desire to investigate the concerns we have about our practice and to push ourselves in our own growth as anti-racist practitioners, we decided to engage in a professional development activity modeled on the type of critical narrative inquiry we ask of our students. For many years, we regularly have asked our students to write narratives (for example, literacy autobiographies, linguistic autobiographies, cultural identity papers, teaching stories) to prompt critical reflection in our teacher education classes. Similar to these class projects that we assign our students, in this self-study, we wrote brief narratives about our teaching practice upon which we wished to reflect further. We shared these narratives with each other and with colleagues. We listened carefully to the responses, trying to understand our practice in new ways through the multiple lenses of our colleagues’ perspectives, for as Loughran (2007) points out:

Although the term self-study suggests a singular and individual approach to researching practice, the reality is that self-studies are dramatically strengthened by drawing on alternative perspectives and reframing of situations, thus data, ideas, and input that necessitate moving beyond the self. Moving beyond the self also matters because a central purpose in self-study is uncovering deeper understandings of the relationship between teaching about teaching and learning about teaching. (p. 12)

Our goal was to access alternative ways to read our practice. The project did not disappoint us. Like turning over a rock to discover life behind what appears to be a benign façade, our awareness was heightened about difficult topics that took some excavation to see.

In this paper, we share the new knowledge gained from this activity as we worked to cycle it back into our practice. We report on a collaborative self-study in which we reflect upon 
difficult teaching moments. We offer insights into the tensions inherent in being white teacher educators for social justice, and we describe a powerful professional development tool. We aim to practice what we preach, as we model our commitment to being life-long learners, our respect for the power of listening to others and considering multiple perspectives, and our constant desire to critique and transform ourselves and pedagogies in ways that are more effective and contribute to the educational success of all students.

\section{Theoretical Framework}

Our collaborative self-study is grounded in two intersecting theoretical frameworks: critical multiculturalism (see McCarthy, 1990; McLaren, 1994 and Sleeter, 1996) and critical race theory, particularly critical whiteness studies (see Hill, 1997; Kincheloe, Steinberg, Rodriquez \& Chenneault, 1998; Ware \& Back, 2002). ${ }^{1}$ Both of these perspectives require that we take a reflexive stance, facilitated in our investigation through critical narrative inquiry (see the following Methods of Inquiry section for details on reflexivity and critical narrative inquiry).

Like the critical race theory scholars who ground our work, we believe that "racism is normal, not aberrant, in American society. Because racism is an ingrained feature of our landscape, it looks ordinary and natural to persons in the culture” (Delgado \& Stefancic, 2000, p. $x v$ ). The field of critical whiteness studies carries the tenets of critical race theory and its examination of how race is implicated in societal structures (such as the legal system and schooling) and applies such an examination to whiteness in particular. It examines and challenges how whiteness and white supremacy and racial privilege provide systematic underpinnings to continued racism and inequity in society.

Critical multiculturalism calls for a change in how we understand knowledge, difference, and action:

[Critical multiculturalism is] the radical redefinition of school knowledge from the heterogeneous perspectives and identities of racially disadvantaged groups--a process that goes beyond the language of 'inclusivity' and emphasizes relationality and multivocality as the central intellectual forces in the production of knowledge. (Gasbarro \& Matthews, 1994, p. 5)

This perspective asks that we move beyond either minimizing or universalizing difference, or emphasizing or exoticizing otherness. Like critical whiteness studies, it calls for the acknowledgement of privilege and the ways it operates to reproduce inequity. It requires a reorientation from an ethnocentric perspective to a consideration of diverse, contradictory, and marginalized (or silenced) interpretations. It demands that we challenge social and structural inequity and commit ourselves to carrying our critique into transformative action.

These perspectives guided us as we designed our self-study. To reflect upon difficult moments in our teaching, we knew that we must look beyond ourselves and invite multiple voices to challenge us. This would push us to move beyond a personal critique, "where theory is dismissed in favor of one's own personal and cultural history" (McLaren, 1994, p. 52), to an examination of social and historical constraints and how they constitute power and inequity. In other words, we knew that we must situate ourselves and understand our own natures as products of systems that reproduce inequity and understand that this location limits our perspectives. This critical perspective requires that we are vigilant of our own privilege and the way it works to keep us on paths of the least resistance (Johnson, 2001) and perpetuators of the status quo. Like 
this study, our pedagogy of teacher education is also rooted in critical multiculturalism and critical race theory as we attempt to help students examine their own power and privilege, the ways in which they have been complicit with racist systems and the ways in which they can fight against such systems. For example, in Michelle's program, she discusses, in social foundations courses, how schooling is historically founded on supremacist systems; in classroom management discussions, the systems which disproportionately funnel students of color into suspensions and expulsions are examined; and in diverse learners classes, preservice teachers examine their own privilege and the ways in which this privilege becomes instantiated in classrooms. Emphasis on systems and individuals is interwoven as we consider how we, as individuals, are impacted by systems and how we, in turn, can impact and change those systems and empower K-12 students to do so as well.

A critical multiculturalism perspective requires that the interrogation of the culture of whiteness be central to our analysis. Without this examination, whiteness remains as the "cultural marker against which otherness is defined....White groups need to examine their own ethnic histories so that they are less likely to judge their own cultural norms as neutral and universal" (McLaren, 1995, p. 50). Our study is informed by scholarship in critical whiteness studies which attempts to understand the multiple performances of whiteness (for example, Clark \& O’Donnell, 1999; Fine, et al, 1997; Frankenberg, 1993; Jones, 1999; King, 2000; Kivel, 1996; McIntyre, 1997; Landsman, 2001; McLaren, 1997; Perry, 2002; Rodriquez \& Villaverde, 2000; Rios, 1996; Sheets, 2000, 2001; Sleeter \& McLaren, 1995). This scholarship has revealed the ways whiteness operates through discourse, the "socially accepted associations among ways of using language, of thinking, valuing, acting, and interacting, in the 'right' places and at the 'right' times with the 'right objects'(Gee, 1999), as the unmarked norm. We acknowledge the importance of interrogating our own points of privilege as white teacher educators and helping students critically analyze their privileges whether linked to race, class, sexual orientation, language, religion, or able-bodiedness.

Critical multiculturalism and critical white studies remind us that complacency is not an option and demands that we not only "talk the talk," but "walk the walk." Using vocabulary that reflects multicultural principles or talking about teaching for social justice is not enough--we must live these principles and model them. "Embracing diversity" has lost its power (Benton, 2006) as this phrase increasingly is used as a feel-good descriptor of attitude; instead, our central task is personal and institutional/structural transformation so that all groups receive equitable opportunities for educational success (McLaren, 1994). We understand that this is a rather tall order. We know that our locations as white, middle-class, native English speaking, heterosexual, able-bodied academics afford us positions of dominance and privilege and may contribute to our own lack of awareness or our inability to act for social justice. We see our on-going professional development about these issues as a necessity. We must constantly commit to and engage in questioning, challenging, and, most importantly, changing our practice. This is almost impossible to do in isolation, and for this reason we designed, participated in, and studied our own professional development intervention.

\section{Methods of Inquiry}

\section{The Authors}

In this collaborative, qualitative self-study, each investigator took on the roles of participant and researcher. One author-participant (Mary) is a faculty member at a large public 
university (enrolling approximately 50,000 students) in an urban area on the east coast who works with a mixture of graduate and undergraduate students who are racially, ethnically, and linguistically diverse. The other author-participant (Michelle) is a faculty member at a small, public, liberal arts university (enrolling approximately 2,000 students) in a rural area in the Midwest who works primarily with students who comprise a fairly homogeneous group of undergraduates, similar in terms of race, ethnicity, and language (i.e., white, EuropeanAmerican, monolingual students).

Mary works with preservice teachers who plan to teach language education, either English language learners or world language learners. Her course and program goals are driven by a critical, sociocultural understanding of language acquisition as occurring through participation in situated social practices and through membership in social groups (Johnson, 2005). This perspective, which helps us understand how language is intertwined with identity and with culture, serves to inform our thoughts about how language acquisition is negatively affected when individuals and groups are marginalized, segregated, and devalued. This perspective is shared with the future teachers, helping them to understand the inequities inherent in educational and broader societal systems, to reflect upon their and their students' identities and locations within these systems, and to consider how they can assume the role of advocate for linguistic and culturally diverse students. At the same time, the goal is that these future language teachers will begin to see the potential for their roles as advocates for promoting multilingualism and intercultural competence for all students, faculty, and administration.

Being located in a fairly homogeneous setting, Michelle most often works with students from rural and suburban backgrounds, with only a few students from urban locations and schools. The course and program goals of Michelle's institution have evolved in response to the experiences and philosophies of the instructors and to the demographic makeup of the students. These goals include a sustained examination of whiteness and white privilege, helping students to see and understand inequities in schooling as a system, and empowering students to create alternate identities for themselves as anti-racist, activist, ally white teachers. The study being discussed in this paper is one method by which Michelle hoped to enhance her practice and her growth in this type of teacher education.

We are aware that our unique subject locations influence our interpretations. For that reason, we designed this project so that our collaboration and the act of involving others in the interpretation process would push us to grow beyond our limited individual capacity to understand some of the factors at play in difficult moments in our teaching.

\section{Research Questions}

We designed our study to help us answer the following questions: How can telling teaching stories about difficult teaching moments lead to greater reflection and reflexivity? Can sharing and analyzing stories enhance teacher education practices that further critical multicultural goals? What do multiple readings of our practice teach us about our teaching?

\section{Project Design and Orientation}

To answer these questions, we each engaged in the following activities (a) wrote a story about something in our teaching upon which we wished to reflect further, (b) shared our stories with each other and other colleagues, (c) analyzed the stories through the multiple lenses offered 
through the responses, and (d) worked to find ways to change ourselves and our practice as a result of engaging in this professional development activity.

Our investigation draws upon critical narrative inquiry, specifically scholarship on the use of narratives as pedagogical tools. The use of narratives as pedagogical tools in teacher education is a trend that employs stories (Abt-Perkins and Gomez, 1993; Gomez and Abt-Perkins, 1995; Gomez, 1996; Gomez, Page, and Walker, 2000; Gomez \& Tabachnick, 1991, 1992; Jalongo and Isenberg, 1995; Nuemann and Peterson, 1997; Ritchie and Wilson, 2000) to engage preservice teachers in critical reflection (Zeichner, 1992; Zeichner and Tabachnick, 1991). Proponents of using narratives for critical inquiry show how teachers' stories "can become what feminist theorist Teresa de Lauretis (1984) calls a 'critical instrument' illuminating the ideologies--the stories--by which their lives and teaching practices are constructed" (as cited in Ritchie \& Wilson, 2000, p. 21). This perspective draws upon feminist notions in its acknowledgement and consideration of personal development in tandem with professional development and the inevitable politics inherent in personal and professional realms. It also draws upon the postmodern perspective that views narrative, through its temporal, spatial, and discursive structure, as inherently partial, subjective, and situational. Through analysis, narrative choices become visible and reveal "the deep connections between cultural stories, personal stories and, ultimately, the interpretive fabric of thought itself” (Freeman, 2001, p. 287).

As we often use narratives and their power for revealing meaning-making processes as situated sites for critical reflection with our preservice teachers in our own teaching, in this study we drew upon their power to teach us, the teacher educators. We each wrote a story focusing on incidents in our teaching that were troublesome and deserving of inquiry. We deliberately refrained from analysis during this phase, wanting to concentrate on telling the story and allowing our readers to make up their own minds as to the themes or key issues upon which they would comment.

After sharing our stories with each other, we sent them via email to seven outside readers for their feedback. We wanted to add their voices to our stories with the hope that they would help us discover new ways of interpreting, understanding, or acting in the types of situations we described.

This phase of the project drew upon Bakhtin's ideas about identity (Holquist, 1990). Bakhtin (1981) writes of how selves are constructed in relationship to and with others. There cannot be an "I" without an "other". The other holds up a symbolic mirror that shows us who and how we are. Bakhtin (1981) gives the example of two people sitting at a table across from each other. In such a scenario, there will be aspects of the scene that one person sees that the other does not--the wall behind the person, perhaps a window and what is outside. Similarly, the second person will see things that the first does not. Bakhtin (1981) calls this "surplus of vision."

For in order to see our selves, we must appropriate the vision of others. Restated in its crudest version, the Bakhtinian just-so story of subjectivity is the tale of how I get my self from the other: it is only the other's categories that will let me be an object for my own perception. I see my self as I conceive others might see it. In order to forge a self, I must do so from the outside. In other words, I author myself. (Holquist, 1990, p. 28)

This idea is similar to Qualley's (1997) notion of reflexivity. Qualley writes how, unlike reflection, which originates and dwells in the self, reflexivity “occurs in response to a person's 
critical engagement with an 'other'” (p. 11). Reflexivity develops through contact with others, in which we compare our current conceptions with new information and perspectives. It is through the juxtaposition of the two, which often reveals their incompatibility, in which "we are compelled to identify and examine our own underlying assumptions” (p. 12). Then, “once we articulate these tacit beliefs, they themselves become open to reflection, critique and perhaps transformation” (p. 12).

To gain this surplus of vision and engage in reflexivity and to honor the need for selfstudy, which does not deteriorate into rationalization or self-justification (Loughran, 2007, p. 13), we shared our stories with others and listened to their multiple perspectives. We specifically invited readers who were different than us in some way--in terms of educational philosophy, life experiences, regional location, culture, race, gender, or language--to serve as our "critical others." We also chose people whom we trusted to challenge us in our thinking and to respond honestly--even if what they said would be painful to hear. All of the respondents were individuals who espoused the critical perspectives that were guiding our work and appeared to live out these perspectives in their personal and professional activities. The seven readers included two urban public school teachers (elementary and middle school); a director of Minority Student Programs on a college campus; a coordinator of a university Diversity Community Outreach Program and three teacher educators. Of the seven, two were men; three were people of color. While all are differently situated in some ways, all work in the field of education and are guided by the desire to work for social justice.

\section{Data Sources: The Stories and Responses}

\section{The Stories}

Our stories focus on our experiences with individual students in our programs. We will briefly describe them here. Full versions of the stories can be accessed at the authors' websites (facultypages.morris.umn.edu/ pagem/teachingstories.html).

Mary’s story, “Learning from Experience, Or Letting Experience Pass You By,” focuses on a student's reaction to some guests who visited her Language and Culture class. She had invited a group of adult English language learners to join her students and engage in small and large group discussions about language and culture border crossing experiences. At one point in the class, one of the visitors, Miguel,,$\frac{3}{}$ spoke passionately to the students, urging them to keep learning more about new immigrants and their cultures. He reminded them that they would be the future teachers of their children, and he cautioned them not to think that new immigrant parents do not care about their children. He explained that they may not go to PTO meetings--not because they do not care--but because they are working two jobs, or they do not feel that their English is good enough to communicate, or they may think that the teachers do not care about what they have to say.

Mary writes about how powerful it was to hear Miguel speak to her students. However, the gist of her story revolves around a student, a white, preservice, world language teacher, who came to her office the next day to be paired with a partner for a group project. The student was told her partner was Miguel, the man who had spoken so eloquently. Mary was crushed when she reminded the student of Miguel's impassioned words the evening before and the student said she could not remember Miguel or what he had said.

Mary ends her story: 
What I learned (or unlearned) is that I cannot assume that I've changed my students. We can orchestrate experiences for them; we can ask that they reflect, hoping to help them grow and unlearn taken-for-granted norms. We hope to better prepare them for future decisions and actions. The difficult thing is ensuring that this learning will happen. There's no guarantee. This experience showed me that I need to go back and invest more energy into my pedagogy so that I can improve the chances that the learning outcomes I'm looking for will happen. (M. Curran, personal communication, March 1, 2004)

Michelle's story, “Michael and Me: A Teaching Story," tells of her experiences with a Vietnamese American student. She writes of how pleased she was initially when Michael Phan joined the secondary education program, thinking that he would provide important alternate perspectives from those of her White students. However, she describes how, after a time, Michael alienated some peers, students he taught, and faculty members through behaviors that were perceived as sexist. He began to have trouble academically. Michelle describes her own interactions with Michael and attempts outside of class to help him, as well as a male faculty member's attempt to reach out to Michael; however, this only seemed to make him quite angry and resulted in his dropping out of the program. Michelle writes of how her interactions with Michael made her very uncomfortable, as she, too, felt on the receiving end of sexist and threatening behavior. Michelle discusses her feelings of being "acutely aware of my own lack of knowledge.”

\section{Michelle ends her story:}

At the end of the semester, Michael gave me a hug--and another gift. He told me how much he wanted to be a teacher and that he would be back to try again. Some of my colleagues are ready to write him off but others of us aren't so sure. I do know that if Michael comes back to our program that I'll need to be more prepared to know about him as an individual and group member and more ready to take risks. (M. Page, personal communication, March 1, 2004)

\section{The Responses}

Our readers were asked to read the stories and respond to them. They were not given specific questions, but were asked to respond to the stories informally, in whatever way they wished. ${ }^{4}$ All of the participants responded via email, except one who responded over the telephone (her comments were written by one of the authors at the time of the call). Our stories and the responses they generated served as our primary data sources. Examples of responses are quoted in the section "Challenging Our Stories” below.

\section{Data Analysis}

Each author coded the stories and responses for the themes, patterns, and tensions that emerged from our close readings and rereadings of the data. We shared our coding results with one another and condensed the coded categories to the main themes that surfaced in the responses to the stories. Some of these themes were the need for integration of content throughout our courses, avoiding “one-shot” attempts at teaching particular concepts, and the ways our identities influenced our teaching. Another was the complexity of lived experience, both our students' and ours. In the case of Michelle's story, for example, issues of race and culture intertwined with issues of communication and gender. Finally, struggle was a theme--the struggle to understand 
the experiences and crafted narratives, struggle to have a "thick skin" and to be open to hard truths. The complexities and struggles that we encountered merit close examination of our narrated experiences and the need for an outside, critical perspective. This was true for ourselves and for our own learning through this project, but we also wanted to think about how to translate this to our own teacher education students and help them to work through difficult issues as well.

We then analyzed the stories through the lenses of these themes. As we reflected upon what our analysis revealed, we worked to reinterpret events and imagine other possibilities in light of our readers' responses. The beginning themes were expanded and transformed as we considered the information and analysis from the respondents who read and commented on the stories (discussed in the next section). We also worked to incorporate the new knowledge from this professional development activity into our teaching philosophies and practice (discussed in the "Changing Our Stories" section). We wrote initial drafts of this paper that we shared with our critical others, so that we could include their feedback on the dissemination of the results of the activity.

\section{Challenging Our Stories}

As we mentioned earlier, a critical multiculturalist perspective requires critiques of the ways knowledge and difference are constructed. This critique, then, must be channeled into transformative action. In this section, we discuss four themes that emerged from the combination of our analysis of the stories and from the responses of our "critical others" to them: (a) assumptions about student learning, (b) holding students accountable, (c) our socialization as white women, and (d) our location within the academy of higher education. In the following section, we discuss implications for practice and how we are changing as a result of engaging in this self-study.

\section{Assumptions About Learning}

First, the stories and responses to them (which we call Responses to Stories or RTS) prompted us to re-examine our assumptions about learning, especially the way we seemed to expect learning to happen automatically. One respondent reminded us about how teacher educators cannot take a "drive-by approach" to issues of equity (Respondent1, RTS, March 30, 2004). Respondent 1 suggests that providing one-time experiences for our students does not have a big enough impact because students are not able to engage in others' realities. She writes that a "necessary change agent” is to "walk a mile in someone else's shoes.” Another writes:

We assume that limited, somewhat disjointed experiences will operate to challenge assumptions, change students and give them the tools to be different kinds of teachers. It is flawed thinking. Even all those students who reported a self-change may have had a brief opportunity to rethink something, but these experiences in general are insufficient. (Respondent 2, RTS, April 5, 2004)

Both Respondent 1 and Respondent 2 remind us how simply taking a class, being present and participating in class activities is not enough.

Another respondent points to the superficial and routinized nature of education, commenting on how this works against the possibility of engaging deeply in learning.

So many students are proceeding through the ritual of doing what must be done to get the credential and "posturing" to advance the impression that deep learning is happening, but are rarely stopping long enough (before proceeding to the next ritual 
whether it be the next class, work, the next football game or whatever) to have a deep experience. We are all moving too fast and as a result everything becomes superficial and that superficiality becomes "functional" in that it allows us to NOT have the difficult conversations and take the risky steps. We are all passing through rather than stopping. It's part of what Foucault calls “normalization.” (Respondent 3, RTS, April 2, 2004)

In other words, our focus on "functioning” keeps us numb and unavailable to learning and change. Many of us are used to going through the motions, which is much easier than confronting the uncomfortable issues that arise when dealing with issues of social justice. This analysis challenges us to interrogate our own practice specifically but also to consider teacher education and our teacher education programs structurally.

\section{Holding Students Accountable}

Similarly, when confronted with students whom we couldn't reach, our respondents asked us why we hadn't responded in a more direct and assertive way and held our students accountable for learning. One respondent writes:

The student who didn’t recognize Miguel or remember him was proof to me that, as I have always argued, racism makes you "stoopid." Why did you [Mary] not challenge this student with the questions: "Why don't you remember someone who said something so important? Why is Miguel so trivial to you?” Or, how about this, “Since you weren’t listening I want a three page paper on why you can't hear Miguel or remember who he is, and if I don't get it from you by this date I will remember to give you a 'D.'”' (Respondent 4, RTS, March 4, 2004)

Another comments, “it made me uncomfortable to think, why isn't she [Michelle] doing something now?” (Respondent 5, RTS, April 2, 2004). We were reminded how our failure to hold students accountable may contribute to their lack of success:

No one was able to clearly articulate to the student what the expectations (around his behaviors) were for fear of being labeled a racist. Instead, the student gets passed on from person to person, teachers begin to avoid him while continuing to do a disservice to him. This is one of the ways in which students fall through the cracks in higher education. (Respondent 1, RTS, March 30, 2004)

A respondent advises us that we all would be better scholar activists if we were "willing to fight for admission and continuation requirements that would include an active anti-racist stance" (Respondent 2, RTS, April 5, 2004). This reflects an emphasis on challenging programs and policies as well as individual practice.

\section{Our Socialization as White Women}

These responses to our stories point out how by not holding our students accountable and challenging them more directly, we abandon our responsibilities as teacher educators for social justice. One respondent links this to an act of "white privilege when we pass students [teacher education students/preservice teachers] who are down-right bad for historically marginalized students” (Respondent 2, RTS, April 5, 2004). Several respondents suggest that the way we interact with our students has been conditioned through our socialization as white women. One writes how this has led us to develop conclusions about our students, "based solely on good will, previous perceptions and/or past experiences” (Respondent 6, RTS, April 9, 2004). Another adds 
how as white teacher educators we "are reluctant to hurt feelings and therefore are not direct enough in our responses” (Respondent 7, RTS, March 30, 2004). In addition, women are often socialized to be indirect and nonconfrontational; our analysis and the RTS highlight the possibility that our histories and socialization as white women deeply impact our communication with students.

\section{Our Location Within the Academy of Higher Education}

We are reminded how this mainstream, white "culture of niceness and politeness" operates in much of higher education to work against the possibility of true academic debate (Respondent 2, RTS, April 5, 2004). It allows us to retreat "into a safe academic research and theory place which enabled you [Mary] to support your unwillingness to challenge your students’ racism effectively” (Respondent 4, RTS, March 4, 2004). Academic culture doesn’t leave much space for "difficult and emotional discussions about power and justice” (Respondent 3, RTS, April 2, 2004). What ends up happening is that "we filter out too much before anything in our souls become public" (ibid). This phenomenon of "nice" and "distant" discourse within the academy interacts with the racial and gender socialization that is discussed in the previous section. Thus, this discursive style is not disrupted by our locations within the academy but, rather, is reinforced.

\section{Changing Our Stories}

Our respondents did not fail us in their ability to add a surplus of vision, pushing us to see areas and directions in which we need to invest more energy for our own and our students' growth. The four themes from the responses to the stories became tools that revealed what we had not been able (or had not wanted) to see and to remind us of what we may already know, but struggle to put into practice. This activity reinforced the value of engaging with other voices and “critically look[ing] at [our] own baggage” (Respondent 1, RTS, March 30, 2004).

Engaging in this activity has caused us to question some of our previously held assumptions and change what we believe and how we act. Although we never really expected our students to automatically learn, this discussion has reinforced the importance of designing our curriculum and program components with multiple opportunities to engage in difficult course content and continual follow-up. As one respondent asked the question:

Was there a debriefing session after the first collaboration meeting to reflect on the comments and discussion that took place? As with many new experiences, we may feel so overwhelmed that we do not take in the "important" information. A whole group debriefing session can bring out a variety of observations from different perspectives. Experiences are not enough. (Respondent 7, RTS, March 30, 2004)

This has influenced the sequence of activities on our syllabi as we make sure we have ample time for guided discussions and reflection after important activities--for example, after watching powerful videos or meeting with community members. We also have become more vocal advocates about the necessity to integrate concerns about equity into all components of our teacher education programs and university life. Some examples include: Mary and some colleagues at her institution have written and received internal grant funding for the revision of core courses to include issues of social justice; she has become the faculty advisor for a student organization focused on issues of equity in education; and she has developed several servicelearning opportunities for teacher education students in local and global community settings. 
Michelle has developed a faculty program for a study group centered on equity issues at her campus, continued revising her courses with social justice issues in mind (a constant, neverending process), worked with the Student Affairs unit on diversity and equity issues, led a multicultural student leadership retreat, and participated in a collaborative peer mentoring partnership with a colleague.

In addition to challenging ourselves in our own work, we need to wake our students to learning, challenging them and providing the scaffolding to do more than simply go through the motions. They need to be aware that going through life without having difficult conversations or taking risks while learning is a privilege enjoyed only by some. Those in marginalized positions do not have the luxury of passing through their days in this way, although even those in marginalized positions may choose not to take the challenge of engaging. We must awaken our students to the necessity of doing this difficult work. We must find ways to encourage and reward genuine inquiry. As one response, both authors have created evaluation rubrics for their assignments including criteria with these expectations.

We also have made commitments to reacting more directly to our students when we see discriminatory behavior or attitudes. Mary, for example, writes:

I've begun calling my students more directly on their actions. For example, this year when we engaged in the collaboration with the ESL adult students, I noticed a great deal of hesitancy on the behalf of my graduate students when they arrived to our class. The ESL students had arrived first and had seated themselves at the tables in our room. As my students arrived, several of them entered the room, looked at the ESL students, and came to me to tell me that they would be right back, that they had forgotten something, or had to use the bathroom. They clearly were not comfortable entering a room filled with our new immigrant guests and sitting with them while they waited for class to begin. At the next opportunity alone with my students, I called their attention to this phenomenon, and I asked them why they thought they had this reaction and what it signified. We discussed what this behavior could mean with regard to future interactions they will have in schools and the need to become aware of (what may be unconscious) attitudes and behaviors like this and what we can do to change them. (personal communication, June 1, 2005)

Michelle writes:

During the semester after the original story was written, I very directly told Michael that his interactions with women could ultimately cost him a job, alienate him from people with whom he wished to be friends, or cause him to be perceived in ways that didn't really represent his character. I tried to brainstorm with him ways to communicate that would not negate who he is but would help him to navigate the mainstream, to code-switch....I tried to help him develop some alternate ways to communicate with peers. (personal communication, June 1, 2005)

We have also begun addressing the topic of accountability and our own dilemma about how to assess students' attitudes and behaviors in terms of social justice issues. We talk about this directly with our students to raise their awareness of their responsibility to actively engage in their own learning and to challenge them to change discriminatory attitudes and behaviors. We see how we need to move beyond "guiding" our students, to "flat out [CHOOSING] to attempt to challenge your students’ way of thinking” (Respondent 4, RTS, March 4, 2004). We both have 
begun to make our students aware of our own decision-making process and conflicts with regard to teaching about issues related to social justice. Mary now talks about the-student-who-didn'thear-Miguel with her current students, asking them why they think this student didn't hear and how she should have been held accountable.

However, the question remains: How do we get our students to listen and change? If we strike too aggressively, we may risk turning them off from the beginning and closing down paths of future communication. Our students have become used to "white academic discourse," and we need to make them aware of this and the limitations of this discourse and the way it serves to mask, leave unchallenged, and perpetuate inequity and marginalization. By making them aware, we can create legitimacy for a new kind of academic discourse that intentionally works to make one uncomfortable and challenged. As Mary tells her students that, "if you are comfortable, something's wrong. You're not learning. Learning means change, and change often implies a period of discomfort. Expect to be uncomfortable in this class--that's good. It means you're growing."

Yet, while we agree that we need to take a proactive stance with regard to the accountability of our students' learning, it is not a simple matter. We know the development of intercultural sensitivity and a critical multicultural perspective takes time and is an on-going process. Growth can be incremental, and the journey is not necessarily linear. It can be an elusive process, especially for those in positions of privilege who must develop a new type of consciousness. Peggy McIntosh (1989) describes this well as she writes of her attempts to write her list of white privileges; during the process, if she did not write her thoughts down immediately, they were lost. Because our students come to our classrooms at various locations in terms of their understandings, our responses to them also need to vary. We ask ourselves if aggressive responses to either the-student-who-didn't-hear-Miguel or Michael would have been the best response. Would these students have continued to listen and confront their own privilege or discriminatory behavior? Or, would they shut down and make themselves unavailable for further learning? Yet, as one respondent reminds us, it is not that we need to respond "aggressively" or "angrily”, but that we question and challenge the students (Respondent 5, RTS, April 2, 2004).

To help determine the appropriate responses to our students, we have begun to incorporate additional information-gathering tools in our practice. Michelle is engaging in more in-depth interviews with students before admissions with the hopes of more carefully assessing her students' attitudes regarding issues of equity and is examining ways in which the teacher education program as a system supports or constrains efforts of teaching for social justice. Mary has begun using an assessment tool, The Intercultural Development Inventory (Hammer, 1999), to gain a picture of the level of intercultural sensitivity of her students as they enter their teacher education program. This inventory provides information about how the students respond to difference (for example, if they respond with defensive, minimizing, accepting, adaptive or integrative attitudes or behaviors). Information gathered in this way will help us gauge how to respond to our students, design our curriculum in appropriate ways, and serve as vehicles to offer students feedback on the way they perceive difference.

Several respondents point to the ways our identities as white academic women may be contributing to our students' failure. We are reminded, once again, how our whiteness informs our perspectives and cultural practices (Rodriguez \& Villaverde, 2000) and may work through us to perpetuate the status quo (King, 2000). We need to examine how this identity is linked to a 
dominant mainstream discourse style (Lopez, 1999), which is performed through the avoidance of confrontation or conflict and discussion about sensitive issues such as discrimination.

We are working to overcome the fear (that we have been socialized to) of being seen as confrontational or labeled an ideologue--or, in other words, "the bitchy white person who can't take a joke” (Respondent 2, RTS, April 5, 2004). The responses to our stories force us to ask ourselves: are we protecting our egos and self-esteem at the expense of our work? Are we willing to take the necessary risks to our identities and assume our responsibilities as teacher educators to prepare teachers who are successful with all students? Tim Wise (2005) reminds us that there is not only risk but loss associated with the work of dismantling systems of oppression and working to become anti-racist. However, there is greater loss if we leave systems of oppression intact. Which losses are we willing to suffer? North (2006) states: “Accordingly, educators need to develop additional skills and tools to address the mourning and suffering that often accompany teaching and learning for social justice (Berlak, 2004; Berlak \& Moyenda, 2001)” (p. 527). While we work to deal with our own socialization and emotional issues connected to teaching and learning for social justice, we also work to help our students who may be thrown into emotional crisis by “challenging our deeply internalized 'colonized knowledge”” (p. 527).

We are pained to think that we may be contributing to our students' failure. We know that as white women, we have an additional responsibility as allies to people of color (Kivel, 1996). We know that faculty of color may be less likely to be heard, especially by white students. Research conducted by one of the authors demonstrated how white students view people of color who speak passionately about issues of discrimination as "confrontational and antagonistic" (Curran, 2001). Sleeter (1996) has also written about how white preservice teachers do not hear messages from teachers of color. Macedo and Bartholomé (1999) cite several studies that "capture the antagonistic manner in which pre-service teachers respond to their multicultural education instructors”, and as a result, valuable learning opportunities are discounted because “these prospective teachers' emotional responses often impair their intellectual understanding and mastery of the material being presented" (p. 149). We need to make our students aware of this double bind, how getting emotional, being passionate, and challenging the status quo are natural and normal reactions to injustices. Freire (2000) writes:

The kind of education that does not recognize the right to express appropriate anger against injustice, against disloyalty, against the negation of love, against exploitation and against violence fails to see the education role implicit in the expressions of these feelings.... It's important to stress the “appropriateness” of this anger. (p. 45)

Our students need to see how when behavior is labeled as anger, and therefore, an unacceptable discourse style for (white) polite conversations or academic forums, we deny the possibility for communication and find powerful ways to silence claims of injustice.

We see how our interactions with our students, due to what we perceive as socially acceptable ways of being, may limit the pedagogical impact of our encounters with our students. By couching our messages within "safe, academic, nice, polite" language and behavior, we risk having them become benign so that they blend into the rest of the discourse. These messages may lose their power to awaken our students to inequity and the necessity to engage in change.

Our goal is to help our students to see how we all assume different identities in different social contexts and how these identities are situated within the larger culture and institutional settings within which we participate (Carbaugh, 1996). While it is true that identities are not 
something we can simply choose (Norton, 2000), our awareness of how they are constantly being co-constructed in specific social practices will help us understand how the identity work we engage in can serve to either perpetuate the status quo or allow for the possibility of social change. We see how it is imperative to raise our students' and our awareness of our identities and the limitations of their customary discourses. We can also focus on their dynamic, fluid and multiple natures, seeing them as potential sites for change (Gee, 1999). In other words, while calling our students' attention to the ways their identities and customary discourses may create miscommunication or barriers to their students' success, we can also take advantage of the pedagogical opportunity to show how we can use this knowledge to become teachers that are more successful for all of our future students.

Together with our students, we need to permit the co-construction of new identities and discourses that can be responsible to social justice. We need to speak directly about the identities and privileges (and the discourses through which they are performed) of white women educators with our students and the challenges they present to us as we work to raise their awareness and engage them in working for social justice. We need to show how these identities constrain us in our ability to do the critical work we most value. Furthermore, we need to prompt our teacher education students from mainstream backgrounds to similarly raise their awareness and see the potential discourse collisions (Lopez, 1999) they may have with students from non-dominant backgrounds (as illustrated in Michelle's story). To do this, we engage our students in projects to heighten their understanding of the way whiteness (and other systems of privilege) operate in our society and to provide them with tools to engage in critical reflexivity. The goal with these projects is to help our students understand identities (self and other) and how they are situated and co-constructed within broader social and cultural, historical and political contexts. Writing this paper has reinforced for us the necessity of incorporating others' views into the identity projects, so that our students also can become privy to a "surplus of vision."

This project also compels us to question if academic life hinders our abilities to work for social justice due to the pressures we may feel to posture, perform and appease in order to advance in our careers and receive tenure and /or promotion. Just as our students operate within a power structure and often will "perform" for us, we may do the same dance for our students and administrators as we think of those end-of-semester evaluations; this may limit the risks we take with our students. In the words of one respondent,

There may go your nice course evaluations....But if your department head will support your effort to help students 'unlearn' racism, he or she should understand that there are times when your students may not like you--as is normal. (Respondent 4, RTS, March 4, 2004)

Unfortunately, the academy does not offer a lot of safe spaces to do this kind of work. Evaluations do play a role in promotion, and the type of critical reflexive work we engage in here is undervalued in our profession. In writing this paper we have become even more sensitive to this issue, as we worry about revealing our own naiveté and lack of mastery with regard to these difficult moments in our practice. Yet, we make this paper public to share our concerns and demonstrate how our commitment to carrying out social justice education requires an on-going, often painful or scary, process of discovery and change. 


\section{Conclusion}

While critiques can be difficult to hear, we know they are essential to our growth. We recognize that “you can't be kind all the time--sometimes you have to be strong” (Respondent 4, RTS, March 4, 2004). We need to listen to the "tough love" about our own practice and take this new knowledge and respond by holding our students and ourselves to high standards and accountability with regard to issues of social justice as well. We need to consider how we must change ourselves in order to be successful in this work.

We offer this story of our experience as a model for professional development that can help teacher educators engage in reflexivity and hear multiple perspectives on issues about which they are concerned. It can offer suggestions for actions to support teachers as they critically examine the way their pedagogical choices, identities, relationships with students, and roles within systems of power and privilege are implicated in their quest to teach for social justice. It has offered us a forum for rigorous collegial inquiry, which we think can be easily duplicated. It provides a concrete format for engaging in a collaborative self-study investigation of one's practice. Moreover, engaging in this activity allows us to model reflexive practice for our students.

The telling of teaching stories is part of a long tradition in teacher education. Ritchie and Wilson (2000) state the following:

The interplay of multiple and often conflicting narratives of professional and personal history, we believe, can provide the catalyst for reflection, critique and "revision" that initiate and sustain teachers' capacity to resist confining cultural narratives and to write new narratives of teaching and living, thus recomposing themselves as teachers and as individuals. (p. 7)

This study adds to this rich tradition by showing how narratives that bring in the "other" can be successfully used for the professional development of teacher educators for social justice.

Through telling and inviting others to critique our narratives, we established new learning communities and generated the possibility of creating new knowledge and change. One of the respondents writes how this is essential, because "we cannot work with 'others' unless we have deeply examined our own upbringing, blind spots, fears, hidden prejudices, rage, etc. as well as listened to others do the same" (Respondent 3, RTS, April 2, 2004). We have been urged to a renewed examination of our whiteness and how it operates in our practice. Listening to each other gave us "lots to think about...I have to rethink my own practice in light of these [the stories]” (Respondent 2, RTS, April 5, 2004). Our analysis has shed light on difficult moments, while pointing us to where we need to grow more. We have learned that we cannot be so nice all the time, but most of all, we have learned that we must be strong enough to commit ourselves to learning more. 


\section{References}

Abt-Perkins, D., \& Gomez, M.L. (1993). A good place to begin-Examining our personal perspectives. Language Arts, 70(3), 193-202.

Bakhtin, M. M. (1981). The dialogic imagination: Four essays (M. Holquist \& C. Emerson, Trans. \& M. Holquist, Ed.) Austin, TX: University of Texas Press.

Benton, T. H. (2006, December 8). Love me; I celebrate diversity. The Chronicle of Higher Education, pp. C1, C4.

Bruner, J. (1986). Actual minds, possible worlds. Cambridge, MA: Harvard University Press.

Carbaugh, D. (1996). Situating selves: The communication of social identities in American scenes. Albany, NY: State University of New York Press.

Clark, C., \& O’Donnell, J. (Eds.).(1999). Becoming and unbecoming white: Owning and disowning a racial identity. Westport, CT: Bergin and Garvey.

Curran, M. (2001). Authoring selves: Narratives as a pedagogical tool. Unpublished dissertation: University of Wisconsin, Madison.

Delgado, R., \& Stefancic, J. (2001). Critical race theory: An introduction. New York: New York University Press.

Fine, M., Weis, L., Powell, L., \& Wong, L. M. (Eds.).(1997). Off white: Readings on race, power, and society. New York: Routledge

Frankenberg, R. (1993). White women, race matters: The social construction of whiteness. Minneapolis: University of Minnesota Press.

Freeman, M. (2001). From substance to story: Narrative, identity, and the reconstruction of the self. In J. Brockmeier, \& D. Carbaugh, D. (Eds.), Narrative and identity: Studies in autobiography, self and culture. Philadelphia: John Benjamins.

Freire, P. (2000). Pedagogy of freedom: Ethics, democracy and civic course. NY: Rowan and Littlefield.

Gasbarro, S. L., \& Matthews, D. (1994). New teachers' perceptions of the meaning of the term 'multiculturalism' in preservice education. Paper presented at the annual meeting of the American Educational Research Association, New Orleans, LA.

Gee, J. P. (1999). An introduction to discourse analysis: Theory and method. New York: Routledge.

Gomez, M. L., \& Abt-Perkins, D. (1995). Sharing of teaching for practice, analysis, and critique. Education Research and Perspectives, 22(1), 39-52.

Gomez, M.L. (1998). Narrating my life. In C.A. Grant (Ed.), Multicultural Research: A reflective engagement with race, class, gender and sexual orientation. London: Falmer.

Gomez, M.L., Walker, A.B., \& Page, M.L. (2000). Personal experience as a guide to teaching. Teaching and Teacher Education 16(7), 731-747.

Gomez, M.L., Page, M.L., \& Walker, A.B. (2000). Returning to learn: A second-career prospective teacher struggles with personal experience as a guide for teaching. In D.M. Byrd 
and D.J. McIntyre (Eds.), Teacher Education Yearbook VIII: Research as Effective Models for Teacher Education. Thousand Oaks, CA: Corwin Press, Inc.

Gomez, M. L., \& Tabachnick, B. R. (1992). Telling teaching stories. Teaching Education, 4, 129-138.

Hammer, M. (1999). A measure of intercultural sensitivity: The intercultural development inventory. In S.M. Flower \& M. G. Fowler (Eds.), The intercultural sourcebook: Volume two. Yarmouth, ME: Intercultural Press.

Hill, M. (1997). Whiteness: A critical reader. NY: New York University Press.

Holquist, M. (1990). Dialogism: Bakhtin and his world. London: Routledge.

Ignatiev, N., \& Garvey, J. (Eds).(1996). Race traitor. New York, NY: Routledge.Jalongo, M. \& Isenberg, J. with Gerbracht, G. (1995). Teachers' stories: From personal narrative to professional insight. San Francisco: Jossey-Bass.

Johnson, A. (2005). Privilege, power, and difference (2nd ed.). New York: McGraw-Hill Humanities/Social Sciences/Languages.

Jones, R. (1999). Teaching racism-Or tackling it? Multicultural stories from white beginning teachers. Stoke-on-Trent, England: Trentham Books.

Kincheloe, J.L., Steinberg, S. R., Rodriquez, N. M., \& Chennault, R. E. (1998). White reign: Deploying whiteness in American. New York: St. Martin’s Press.

King, J. (2000). White teachers at the crossroads. Teaching Tolerance, 18, 13-18.

Kivel, P. (1996). Uprooting racism: How white people can work for racial justice. Gabriola Island, BC: New Society Publishers.

Kumashiro, K. \& Ngo, B. (Eds.). (2007). Five lenses for anti-oppressive teacher education: Partial stories, improbable conversations. New York: Peter Lang.

Landsman, J. (2001). A White teacher talks about race. Lanham, MD: The Scarecrow Press, Inc.

Loughran, J. (2007). Researching teacher education practices: Responding to the challenges, demands, and expectations of self-study. Journal of Teacher Education, 58(1), 12-20.

Lopez, M. E. (1999). When discourses collide: An ethnography of children at home and at school. NY: Peter Lang Publishing.

Macedo, D., \& Bartholomé, L. I. (1999). Dancing with bigotry: Beyond the politics of tolerance. New York: St. Martin’s Press.

McCarthy, C. (1990). Multicultural education, minority identities, textbooks, and the challenge of curriculum reform. Journal of Education 17(2), 118-29.

McIntosh, P. (1992). White privilege and male privilege: A personal account of coming to see correspondences through work in women's studies. In M. L. Andersen \& P. Hill Collins (Eds.), Race, class, and gender: An anthology (pp. 70-81). Belmont, CA: Wadsworth.

McIntyre, A. (1997). Making meaning of whiteness: Exploring racial identity with white teachers. Albany, NY: State University of New York Press. 
McLaren, P. (1994) White terror and oppositional agency: Towards a critical multiculturalism. In D. T. Goldberg (Ed.), Multiculturalism: A critical reader (pp. 45-74). Cambridge, MA: Blackwell Publishers, Inc.

McLaren, P. (1995). White terror and oppositional agency: towards a critical multiculturalism. In C. A. Sleeter \& P. McLaren, (Eds.), Multicultural education, critical pedagogy, and the politics of difference. Albany, NY: State University of New York Press.

North, C. (2006). More than words? Delving into the substantive meaning(s) of "social justice" in education. Review of Research in Education, 76(4), 507-535.

Norton, B. (2000). Identity and language learning: Gender, ethnicity and educational change. Reading, MA: Pearson.

Nuemann, A., \& Peterson, P. (1997). Learning from our lives: Women, research, and autobiography in education. New York: Teachers College Press.

Qualley, D. (1997). Turns of thought: Teaching composition as reflexive inquiry. Portsmouth, NH: Boynton/Cook.

Rios, F. A. (Ed.). (1996). Teacher thinking in cultural contexts. Albany, NY: State University of New York Press.

Ritchie, J. S., \& Wilson, D. E. (2000). Teacher narrative as critical inquiry: Rewriting the script. New York: Teachers College Press.

Rodriguez, N., \& Villaverde, L. (Eds.). (2000). Dismantling white privilege: Pedagogy, politics, and whiteness. New York: Peter Lang.

Rosenwald, G. C., \& Ochberg, R. L. (1992). Storied lives: The cultural politics of selfunderstanding. New Haven, CT: Yale University Press.

Sheets, R. H. (2000). Advancing the field or taking center stage: The white movement in multicultural education. Educational Researcher, 29(9), 15-21.

Sheets, R. H. (2001). Whiteness and white identity in multicultural education. Multicultural Education, 8(3), 38-40.

Sleeter, C. E. (1996). Multicultural education as social activism. New York: SUNY Press.

Sleeter, C. \& McLaren, P. (Eds). (1995). Multicultural Education, Critical Pedagogy, and the Politics of Difference. Albany, NY: State University of New York Press.

Ware, V., \& Back. L. (2002). Out of whiteness: Color, politics, and culture. Chicago: The University of Chicago Press.

Wise, T. (2005). White like me: Reflections on race from a privileged son. Brooklyn, NY: Soft Skull Press.

Zeichner, K. (1992). Educating teachers for cultural diversity. East Lansing, MI: National Center for Research on Teacher Education.

Zeichner, K.M., \& Tabachnick, B. R. (1991). Reflections on reflective teaching. In B.R. Tabachnick \& K.M. Zeichner (Eds.), Issues and practices and in inquiry-oriented education (pp.1-21). New York: Falmer. 


\section{Endnotes}

${ }^{1}$ Critical whiteness studies is often considered to be an offshoot of critical race theory. Critical race theory provided many of the foundational ideas that support critical whiteness studies, particularly the scholarship on power relationships (such as Ignatiev and Garvey, 1996).

$\underline{2}$ A version of this story also appears in a chapter written for Innovations in Anti-Oppressive Educational Research and Practice: Five Conversations. (Kumashiro and Ngo, (2007).

$\underline{3}$ All names in stories are pseudonyms.

${ }^{4}$ One reader, Respondent4, read the stories in a slightly different draft version. 